\title{
Estimation of the perpendicular-to-the-grain tensile strength of Scots pine glued laminated timber via three-point bending tests
}

\author{
Shigefumi Okamoto ${ }^{{ }^{*}} \mathbb{D}$, Nobuhiko Akiyama ${ }^{2}$, Noboru Nakamura ${ }^{3}$, Kenji Aoki ${ }^{4}$ and Masahiro Inayama ${ }^{4}$
}

\begin{abstract}
Three-point bending tests were performed on specimens of glued laminated timber with different specimen heights to failure to determine the relationship between specimen height and bending strength under tension perpendicular to the grain. For the three-point bending tests, two types of glued laminated timber composed of homogeneous grade timber, as specified in the Japanese Agricultural Standard, were used. The laminae used for the glued laminated timber were L80 grade Scots pine and L110 grade Scots pine. The specimens used in the three-point bending tests had dimensions of $105 \mathrm{~mm}$ (width) and 10-300 mm (height). The experimental results showed that the bending strength decreased as the specimen height increased, but the rate of decrease in the bending strength decreased with increasing specimen height when the specimen height exceeded $100 \mathrm{~mm}$. From the relationship between the bending strength and specimen height, parameters that fit Bažant's size-effect law were derived, and for a specimen height of approximately $100 \mathrm{~mm}$, the bending strength was equal to the perpendicular-to-the-grain tensile strength.
\end{abstract}

Keywords: Glued laminated timber, Tensile strength, Perpendicular to the grain

\section{Introduction}

The tensile strength of wood is extremely high parallel to the grain and extremely low perpendicular to the grain. The structural design standards for timber structures in Japan specify the parallel-to-the-grain tensile strength, but do not specify the perpendicular-to-the-grain tensile strength. One reason for this is the experimental difficulty of evaluating the perpendicular-to-the-grain tensile strength.

Test methods used for evaluating the perpendicular-tothe-grain tensile strength of timber via tensile and bending experiments have been described in JIS Z 2101 [1], ASTM D143-14 [2] and ISO 13910 [3]. The tension test method is shown in Fig. 1. In the method shown in Fig. 1a [1], the stress is uniformly applied at the center of the

\footnotetext{
*Correspondence: okamoto@osaka-cu.ac.jp

${ }^{1}$ Graduate School of Human Life Science, Osaka City University, 3-3-138

Sugimoto, Sumiyoshi-ku, Osaka 558-8585, Japan

Full list of author information is available at the end of the article
}

specimen; however, the stress becomes nonuniform and the stress concentration increases with increasing distance from the center [4]. Experimental studies have also reported that the tension test specimens shown in Fig. 1a [1] break mainly in the arc region [5]. In the method shown in Fig. 1b [2], the stress does not act uniformly, and the stress concentration is very high [4]. The method shown in Fig. 1c [3] yields different tensile strength values depending on the dimensions $[6,7]$. This is due to the influence of the dimensional effects of Weibull's statistical theory. ISO 8375 [8] also specifies the method shown in Fig. 1c, where the specimen has the following dimensions: $h=400 \mathrm{~mm}, b \geq 100 \mathrm{~mm}$, and $b \times l=25,000 \mathrm{~mm}^{2}$.

The bending test method described in ISO 13910 [3] is shown in Fig. 2. The tensile strength according to the test method in ISO 13910 [3] can be found in Eq. (1):

$$
f_{t 90}=\left(\frac{3.75 \cdot F_{\mathrm{ult}}}{b \cdot h}\right) \times\left(\frac{0.03 \cdot b \cdot L_{h}^{2}}{800^{3}}\right)^{0.2},
$$

Springer Open

(c) The Author(s) 2021. This article is licensed under a Creative Commons Attribution 4.0 International License, which permits use, sharing, adaptation, distribution and reproduction in any medium or format, as long as you give appropriate credit to the original author(s) and the source, provide a link to the Creative Commons licence, and indicate if changes were made. The images or other third party material in this article are included in the article's Creative Commons licence, unless indicated otherwise in a credit line to the material. If material is not included in the article's Creative Commons licence and your intended use is not permitted by statutory regulation or exceeds the permitted use, you will need to obtain permission directly from the copyright holder. To view a copy of this licence, visit http://creativeco mmons.org/licenses/by/4.0/. 

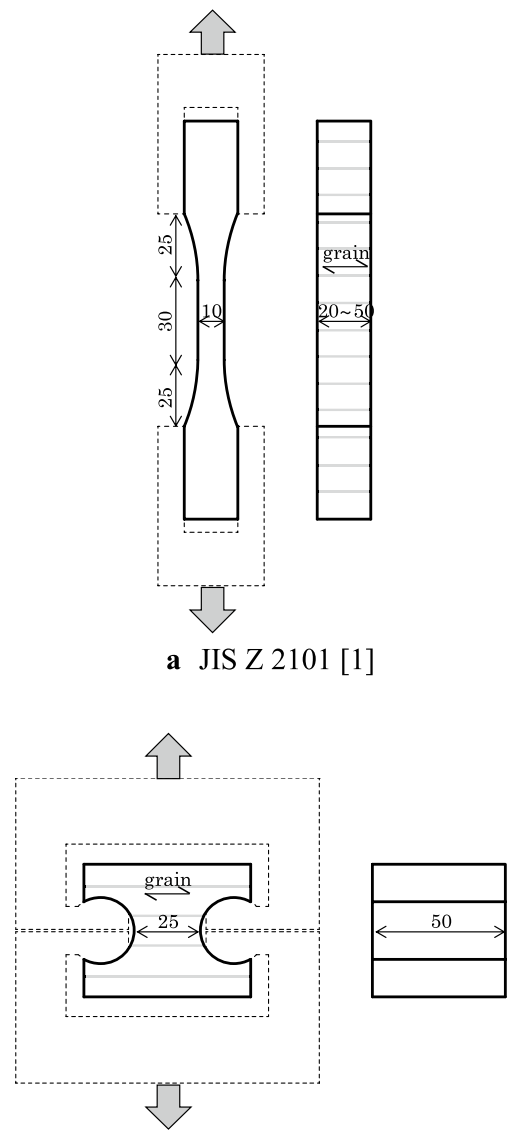

b ASTM D143 [2]

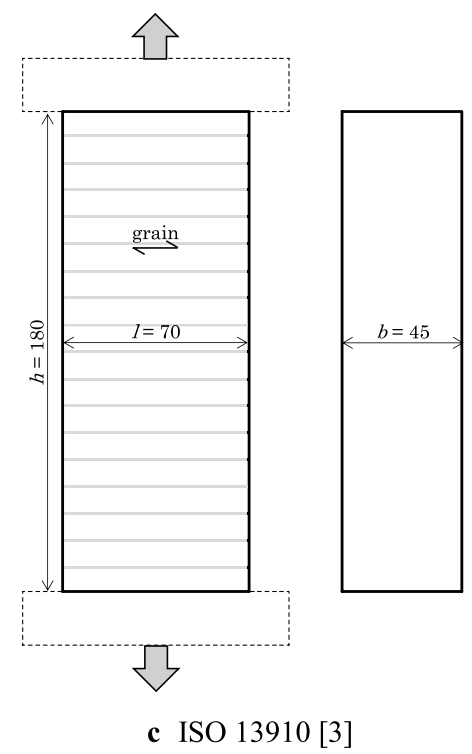

Fig. 1 Tension test methods where $f_{t 90}$ is the perpendicular-to-the-grain tensile strength, $F_{\text {ult }}$ is the value of the applied load at failure.

Equation (1) is equal to $1 / 3$ of the maximum bending stress according to the Bernoulli-Euler theory multiplied by the size-effect factor. Multiplying by the dimensional effect factor normalizes the tensile strength to the equivalent value for a cube of timber with a side length equal to $800 \mathrm{~mm}$. This test method yields a tensile strength of the lowest boundary limit.

Kuwamura [5] performed the bending test shown in Fig. 2 (for a specimen height $20 \mathrm{~mm}$, specimen width $30 \mathrm{~mm}$, and distance between the fulcrums of $100 \mathrm{~mm}$ ) and the tension test shown in Fig. 1a on cuts from the same piece of wood. They reported a flexural strength result that was slightly higher but not significantly different from the tensile strength. Yokobori [9] explained that the dimensional effect in the case of stress gradients such as those due to bending is due to the difference in the average value of stress over a constant length $t$, as shown in Fig. 3. These results indicate that it is difficult to determine the perpendicular-to-the-grain tensile strength by using a tension test and that by using a bending test, in addition to the effect of specimen size, it is necessary to consider the effect of the difference in the average value of the stresses over a constant length.

In a perfectly brittle material containing a crack, the entire fracture process under a tensile loading takes place at the tip of the crack. However, in many materials, such as concrete and wood, the fracture process is not confined to a point and occurs within a certain length, called the fracture process zone, which extends beyond the tip of the crack. This fracture process zone is said to be one of the causes of the size effect on the bending strength.

Hillerborg et al. [10] proposed a fictitious crack model, which is an analytical method that can evaluate the influence of this fracture process zone. Figure 4 shows the analytical results of the fictitious crack model for the unnotched three-point bending tests of concrete [11], where $f_{t}$ is the tensile strength, $f_{f}$ is the bending strength, $l_{\mathrm{ch}}$ is a characteristic length, and $\sigma_{i}$ is the initial stress. In the case of $\sigma_{i}=0$, the bending strength decreases as the beam height $d$ increases and asymptotically approaches the tensile strength. The fictitious crack model has also been applied to wood, and Boström [12] applied the fictitious crack model to the compact tension specimen of wood and reported the influence of different material properties on the experimental results.

Bažant proposed a variety of general equations for describing the size effect of the fracture process zone by asymptotic analysis of the energy release. Bažant first proposed a size-effect law for a structure containing a notch or a stably growing large crack [13]. Subsequently, Bažant proposed Eq. (2) [14] and Eq. (3) [15] by 

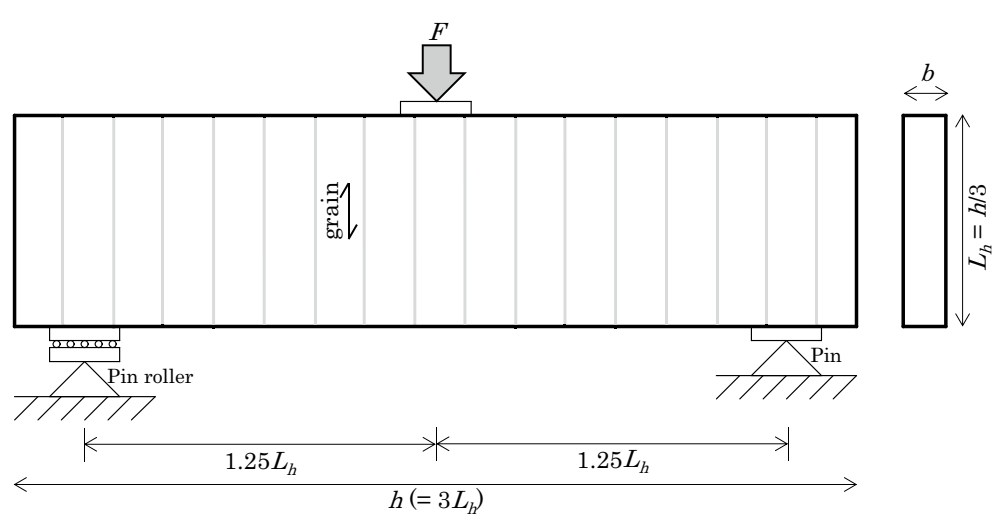

Fig. 2 Bending test method (ISO 13910 [3])

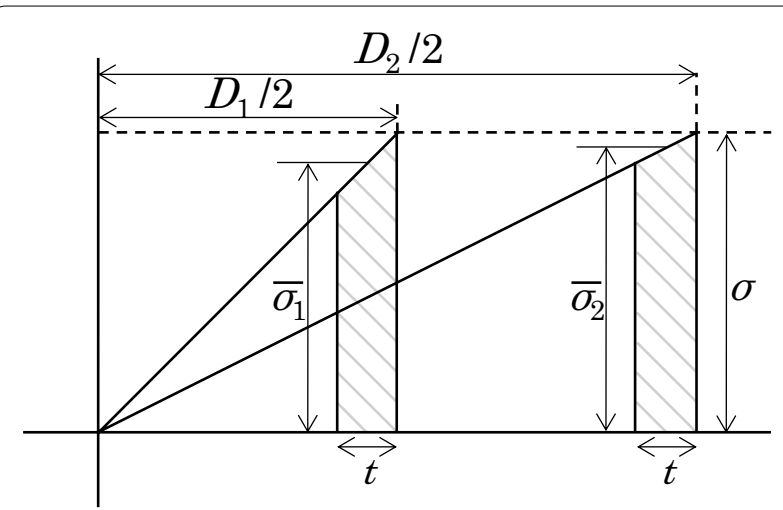

Fig. 3 Size effect of the stress gradient extending the size-effect law [13] for a structure with a crack to a structure without a crack:

$$
\begin{aligned}
& f_{r}=f_{r \infty} \cdot\left(1+\frac{D_{b}}{D}\right), \\
& f_{r}=\sqrt{f_{r \infty}^{2}+\frac{2 \cdot f_{r \infty}^{2} \cdot D_{b}}{D}},
\end{aligned}
$$

where $B$ is the specimen width, $D$ is the specimen height, $f_{r}$ is the nominal bending strength $\left(f_{r}=6 M_{\max } / B D^{2}\right), M_{\max }$ is the maximum bending moment, $f_{r \infty}$ is the nominal

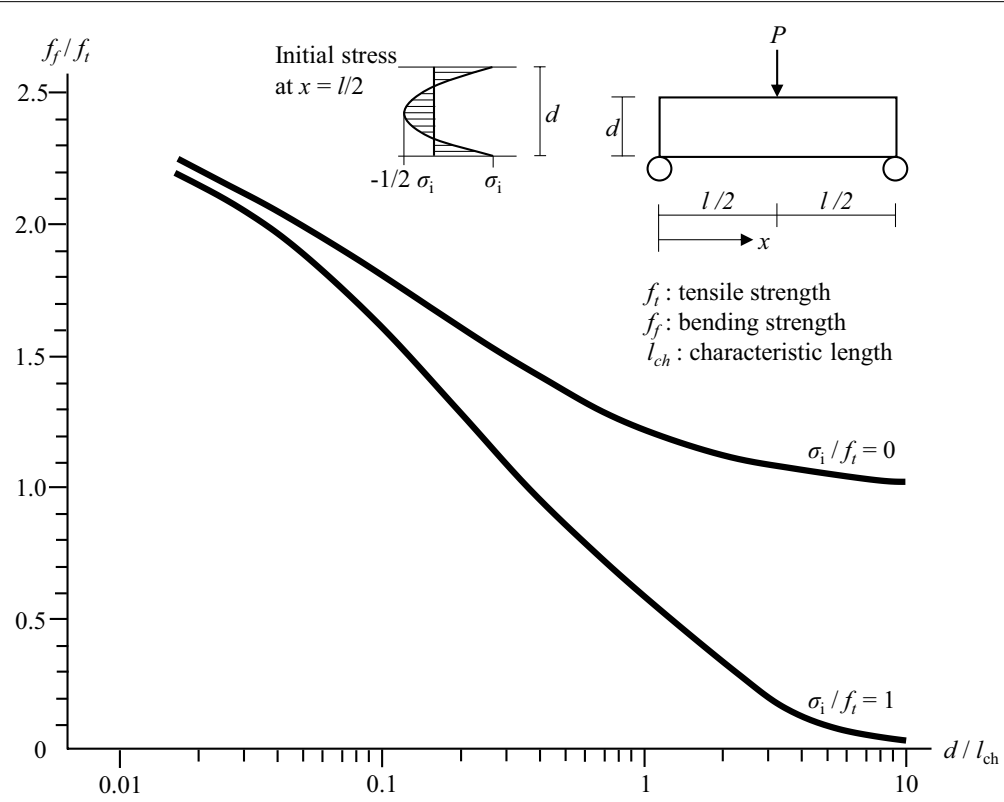

Fig. 4 Finite element analysis results. The figure was originally published in Ref. [11] and shown here with some modifications 
bending strength for a very large specimen height, and $D_{b}$ is a constant length.

After proposing Eqs. (2)-(3), Bažant proposed Eq. (4) [16]:

$$
f_{r}=f_{r \infty} \cdot\left(1+\frac{r \cdot D_{b}}{D}\right)^{1 / r}
$$

where $r$ is an arbitrary positive constant. Equation (2) is used when $r=1$, and Eq. (3) is used when $r=2$.

Equations (2-4) show that as the specimen height $D / D_{b}$ increases, $f_{r} / f_{r \infty}$ decreases and approaches 1.0 , similar to the results for $\sigma_{i}=0$ in Fig. 4 .

The probability of bending failure of a structure without a crack increases as the cross-sectional area of the beam increases because of the presence of a large number of defects at locations of high stress. Therefore, the effect of specimen size must be considered in addition to the effect of the fracture process zone. Therefore, Bažant proposed Eq. (5), which adds the effect of size to Eq. (4) [17]:

$$
f_{r}=f_{r \infty} \cdot\left[\left(\frac{D_{b}}{D}\right)^{r \cdot n / m}+\frac{r \cdot D_{b}}{D}\right]^{1 / r},
$$

where $m$ is the Weibull modulus and $n$ is the number of spatial dimensions $(n=1,2$, or 3 ; in the present calculations, 2). According to existing test data for concrete, $f_{r \infty}=3.68 \mathrm{~N} / \mathrm{mm}^{2}, D_{b}=15.53 \mathrm{~mm}, r=1.14$ and $m / n=12$ are optimal [17].

Aicher [18] evaluated the effect of size on the perpendicular-to-the grain tensile strength in European spruce (Picea abies) notched beam specimens with the Bažant's size-effect law [13] and determined the fracture process zone length. However, no previous studies have applied Bažant's size-effect law [17] to timber without a crack.
Therefore, in this study, the relationship between specimen height and bending strength was investigated by performing three-point bending tests on Scots pine (Pinus sylvestris) glued laminated timber specimens with different heights. In addition, parameters were derived from the relationship between the specimen height and bending strength to fit Eq. (5). Since $f_{r \infty}$ in Eq. (5) is considered to be very close to the tensile strength, we also examined the specimen height at which the bending strength is approximately equal to the tensile strength.

\section{Materials and methods}

For the three-point bending test, two types of glued laminated timber composed of homogeneous grade timber, as specified in the Japanese Agricultural Standard (JAS) [19], were used. The laminae used for the glued laminated timber were L80 grade (8.0-10.0 GPa) Scots pine (L80) and L110 grade (11.0-14.0 GPa) Scots pine (L110). The laminae were 30.3 to $31.6 \mathrm{~mm}$ thick and bonded with phenol-resorcinol-formaldehyde resin. The strength grade of the glued laminated timber made from the L80 laminae is E75-F270 [19]. The strength grade of the glued laminated timber made from the L110 laminae is E105-F345 [19]. Figure 5 shows a schematic diagram of the bending test. The force point and fulcrums were steel with a radius of $15 \mathrm{~mm}$. The specimen width $B$ was $105 \mathrm{~mm}$, and the distance between the fulcrums $L$ was tested at 100,200 , and $500 \mathrm{~mm}$. For $L=100,200$, and $500 \mathrm{~mm}$, the specimen lengths were 150,300 , and $750 \mathrm{~mm}$, respectively. The specimen height $D$ was set to $10,20,30$, and $40 \mathrm{~mm}$ when $L=100 \mathrm{~mm}$. $D$ was set to $10,20,40,60,80,100$, and $150 \mathrm{~mm}$ when $L=200 \mathrm{~mm}$. $D$ was set to $80,100,150,200,250$, and $300 \mathrm{~mm}$ when $L=500 \mathrm{~mm}$. The number of specimens tested was 3 for $D=300 \mathrm{~mm}$ and 6 for each of the other specimen heights. The test specimens were taken from laminated

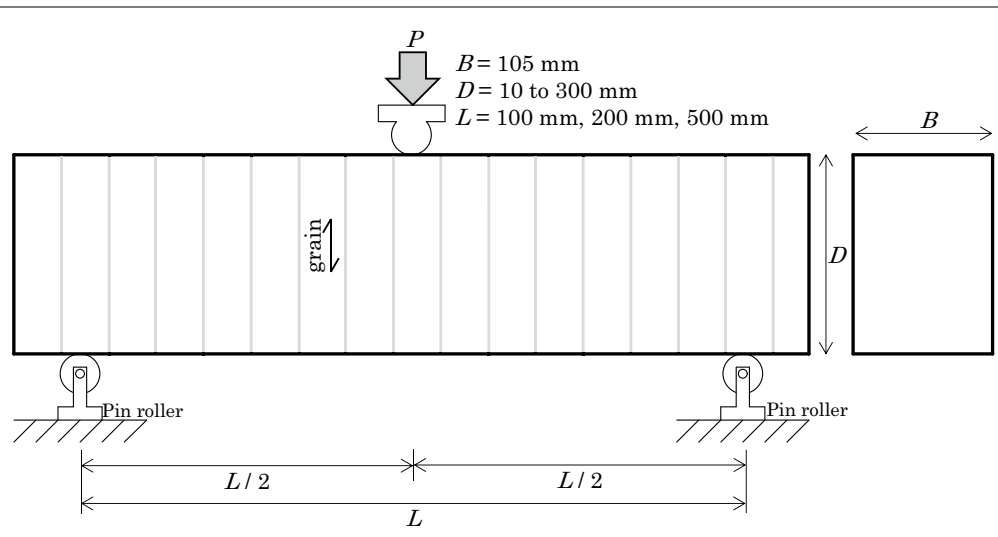

Fig. 5 Three-point bending test method 
wood manufactured with cross-sections with $105 \mathrm{~mm}$ widths and 150, 300 and $750 \mathrm{~mm}$ heights. We did not use a constant temperature and humidity testing chamber, and we did not control the temperature and humidity when the specimens were stored. The mean \pm standard deviation of the density was $480 \pm 14 \mathrm{~kg} / \mathrm{m}^{3}$ for $\mathrm{L} 80$ and $518 \pm 12 \mathrm{~kg} / \mathrm{m}^{3}$ for L110. The mean \pm standard deviation of the moisture content was $9.6 \pm 3.1 \%$ for L80 and $11.6 \pm 2.7 \%$ for L110. The moisture content was measured using a moisture tester (HM-520, Kett Electric Laboratory). The moisture content considered was the value measured for specimens with $D \geq 60 \mathrm{~mm}$. The surface on which the tension of the specimen acted (the underside of the specimen) is shown in Fig. 6. For the experiment, the load was applied at a constant crosshead speed. The crosshead speed was adjusted from 1 to $2 \mathrm{~min}$, from the start of loading to bending failure.

The bending strength $f_{r}$ was determined by Eq. (6) using the maximum load obtained in the experiment:

$$
f_{r}=\frac{3 \cdot L \cdot P_{\max }}{2 \cdot B \cdot D^{2}}
$$

where $P_{\max }$ is the value of the maximum load.

The parameter fitting in Eq. (5) is derived by an iterative method using curve fitting with changing $r$ or $m / n$.

The optimal values of the parameters are obtained by the least squares method using Eq. (7) (linear form of Eq. (4)) and Eq. (8) (linear form of Eq. (5)):

$$
y=A \cdot x+B,
$$

where $y=f_{r}^{r}, x=\frac{r}{D}, A=D_{b} \cdot f_{r \infty}^{r}, B=f_{r \infty}^{r}$

$$
y=A \cdot x+B,
$$

where $\quad y=D \cdot f_{r}^{r}, x=\left(\frac{1}{D}\right)^{r \cdot n / m-1}, A=D_{b}^{r \cdot n / m} \cdot f_{r \infty}^{r}$, $B=r \cdot D_{b} \cdot f_{r \infty}^{r}$.
Curve fitting is determined by the minimum value of the residual sum of squares of $f_{r} / f_{r \infty}$ obtained by Eq. (9):

$$
\mathrm{RSS}=\sum_{i=1}^{N}\left(\frac{f_{r, \text { cal. }}}{f_{r \infty}}-\frac{f_{r, \text { exp. }}}{f_{r \infty}}\right)^{2},
$$

where is RSS is the residual sum of squares of $f_{r} / f_{r \infty}, f_{r \text {, }}$ cal. is the calculated value obtained by Eqs. (4) and (5). $f_{r}$, exp. is the experimental value obtained by Eq. (6). $N$ is the number of all specimens $(N=198)$.

The method of this iterative calculation is described later in this paper.

\section{Results and discussion}

\section{Experimental results}

The final failure state of the side under tension is shown in Fig. 7. Most of the specimens in the three-point bending tests failed at the pith located near the crosshead (Fig. 7a) or at the adhesive layer located on the pith side near the crosshead (Fig. 7b). Figure 8 shows the relationship between the force point load $P$ and the force point displacement $\delta$ of a typical specimen. Table 1 shows the $f_{r}$ (average and standard deviation) of the experimental results.

Figure 9 shows the relationship between $f_{r}$ and $D$ in the experimental results. When $D$ was between 10 and $100 \mathrm{~mm}$, the value of $f_{r}$ decreased significantly as $D$ increased. However, when $D$ was between 100 and $300 \mathrm{~mm}$, the values of $f_{r}$ were almost the same, although there was a slight tendency of $f_{r}$ to decrease. Regarding the difference in $L$, for L80, $f_{r}$ was slightly smaller when $L$ was larger, even though $D$ was the same. However, for L110, there were cases where there was no difference in $f_{r}$ due to the difference in $L$ or where a larger $L$ value resulted in a larger $f_{r}$. Therefore, the variation in strength had a greater effect than the difference in $L$ did on the experimental results.

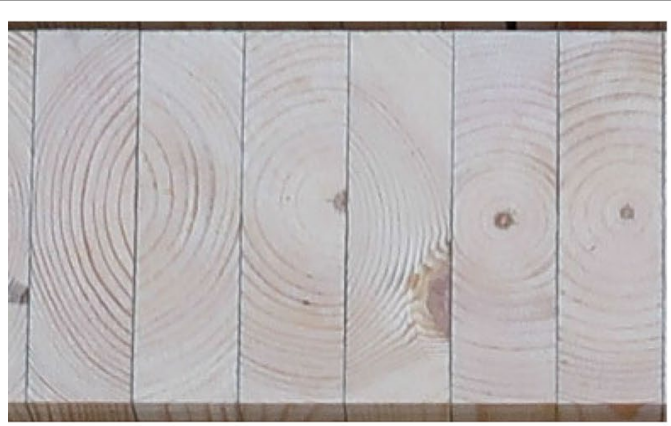

L80

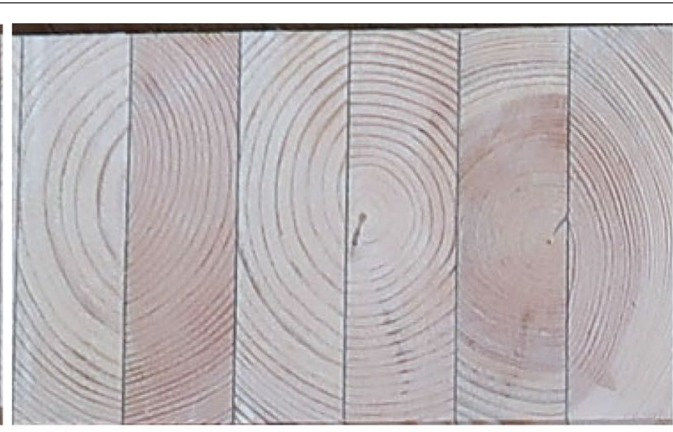

L110

Fig. 6 Lower surfaces of representative specimens 


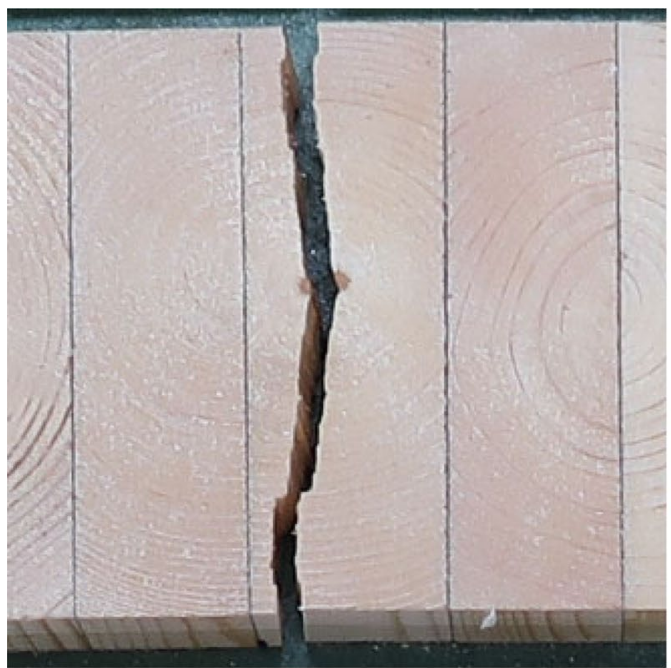

L80

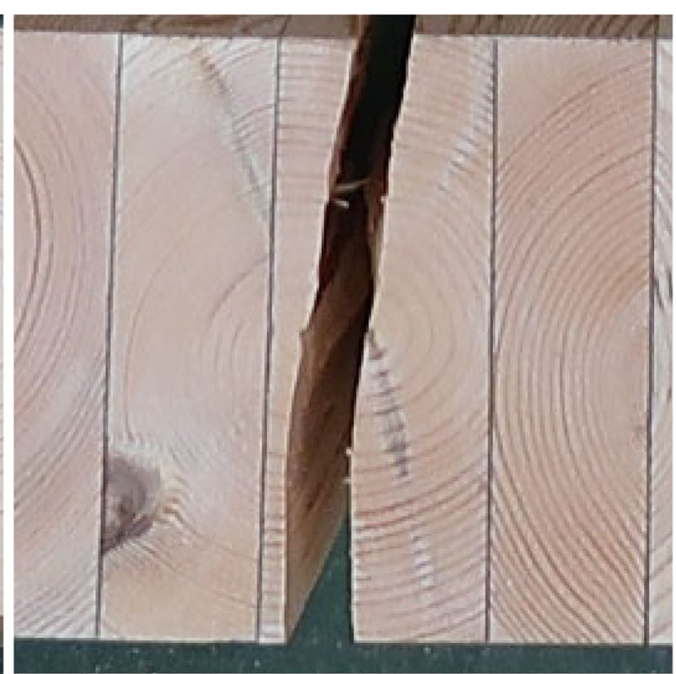

L110

a Fracture from the pith side

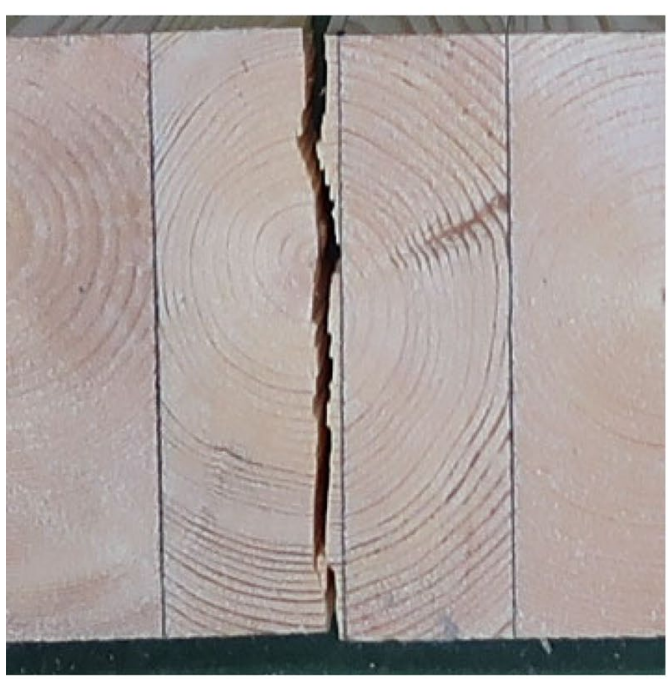

L80

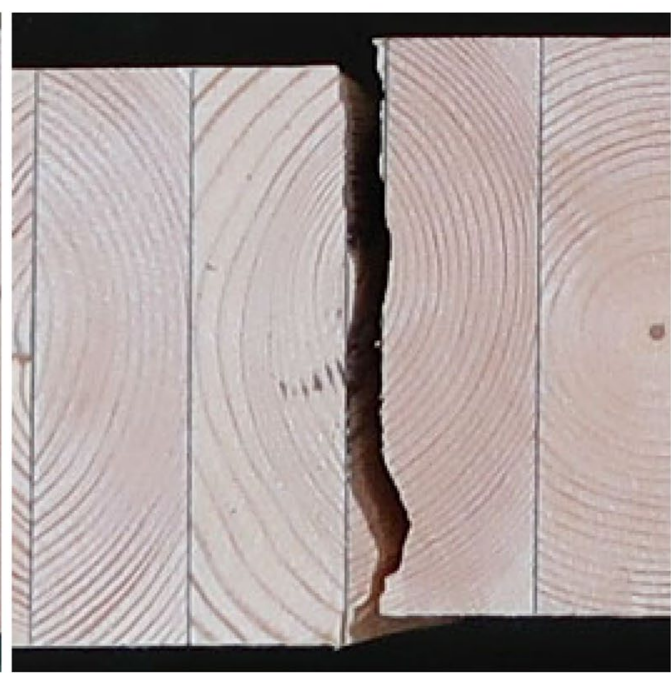

L110

b Fracture from the adhesive joint on the pith side

Fig. 7 Final fracture state of representative specimens

\section{The parameters of the size-effect law}

Bažant et al. [17] assumed that the greatest change from one concrete or one testing approach to another can be described by the values of $f_{r \infty}$ and $D_{b}$ and that the values of $r$ and $n / m$ are approximately the same for different concretes and test series. In this study, this assumption was also applied to wood, and it was assumed that the values of $f_{r \infty}$ and $D_{b}$ are different, between L80 and L110, but the values of $r$ and $n / m$ are the same. We also assumed that $f_{r \infty}$ and $D_{b}$ would be the same for different $L$ because we thought that the effect of different $L$ would be very small in the scope of the present study. The parameters of Eq. (5) were then derived in steps $1-4$. 


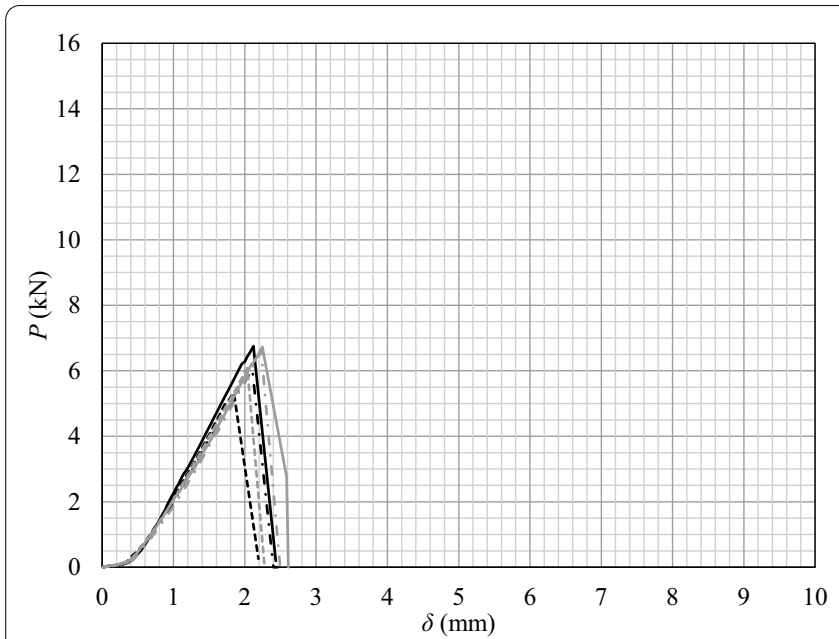

L80, $D=80 \mathrm{~mm}, L=200 \mathrm{~mm}$

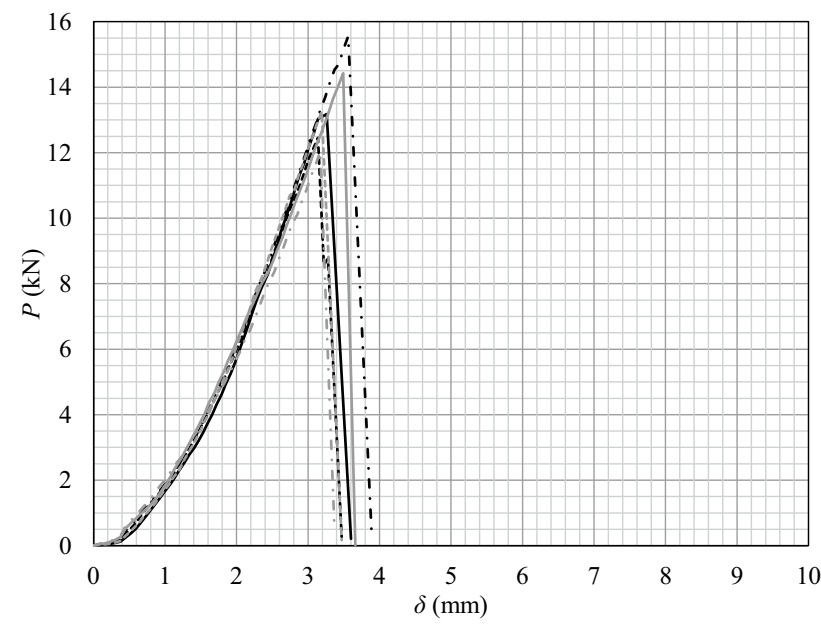

L80, $D=200 \mathrm{~mm}, L=500 \mathrm{~mm}$

Fig. 8 Relationship between the force point load and force point displacement for representative specimens

\section{Step 1}

Using the experimental data of L80 and L110 as different data sets, obtain $f_{r \infty}$ and $D_{b}$ for $r=0.01-3.50$ by the linear regression approximation of Eq. (7). Next, obtain $f_{r}$ using Eq. (4), and obtain the residual sum of squares of $f_{r} / f_{r \infty}$ using Eq. (9) with L80 and L110 as one data set. The optimal value is the parameter when the residual sum of squares of $f_{r} / f_{r \infty}$ obtained by changing $r$ is minimized. Figure 10 shows the relationship between $r$ and $\mathrm{RSS} / N$.

\section{Step 2}

Using the experimental data of L80 and L110 as different data sets, obtain $f_{r \infty}$ for $m / n=4.1-90.0$ by the linear regression approximation of Eq. (8) using the optimal values of $r$ and $D_{b}$. Next, obtain $f_{r}$ using Eq. (5), and obtain the residual sum of squares of $f_{r} / f_{r \infty}$ using Eq. (9) with L80 and L110 as one data set. The optimal value is the parameter when the residual sum of squares of $f_{r} / f_{r \infty}$ obtained by changing $m / n$ is minimized. Figure 11 shows the relationship between $m / n$ and RSS/N.

\section{Step 3}

Using the experimental data of L80 and L110 as different data sets, obtain $f_{r \infty}$ and $D_{b}$ for $r=0.01-3.50$ by the linear regression approximation in Eq. (8) using the optimal value of $m / n$. Next, obtain $f_{r}$ using Eq. (5), and obtain the residual sum of squares of $f_{r} / f_{r \infty}$ using Eq. (9) with L80 and L110 as one data set. The optimal value is the parameter when the residual sum of squares of $f_{r} / f_{r \infty}$ obtained by changing $r$ is minimized. Figure 12 shows the relationship between $r$ and RSS/N.

\section{Step 4}

Using the optimal values of $r$ and $D_{b}$ obtained in step 3 , obtain the optimal values of $f_{r \infty}$ and $m / n$ in step 2 . Then, using the optimal value of $m / n$ obtained in step 2 , obtain the optimal values of $r, f_{r \infty}$ and $D_{b}$ in step 3 . This is repeated until $r, f_{r \infty}, D_{b}$ and $m / n$ do not change. Steps 2 and 3 were calculated repeatedly, and 28 calculations converged with no change in value. Figure 13 shows the relationship between $m / n$ and RSS/ $N$ obtained in step 2 after convergence, and Fig. 14 shows the relationship between $r$ and RSS/ $N$ obtained in step 3 after convergence.

According to existing concrete test data, $m / n=12$ is optimal [17]. Barrett [20] reported a size parameter of 7.68 for the perpendicular-to-the-grain tensile strength of Douglas fir by volume change and a theoretical size parameter of 9 for a beam loaded along a constant width. Based on the above, the $m / n=10.3$ obtained in Fig. 13 is considered to be a reasonable value.

The relationship between $f_{r} / f_{r \infty}$ and $D / D_{b}$ for the experimental and calculated values (Eq. 5) using the optimal parameters is shown in Fig. 15. The calculated values generally captured the experimental values, confirming the applicability of Eq. (5) to Scots pine glued laminated timber. Figure 16 plots the horizontal axis of the calculated values in Fig. 15 as a function of $D$. When the specimen height is $D=80-120 \mathrm{~mm}$, the error of $f_{r} / f_{r \infty}$ is within $5 \%$. Therefore, the bending strength is almost equal to the tensile strength for $D=80-120 \mathrm{~mm}$. 
Table 1 Bending strength of the three-point bending test results

\begin{tabular}{|c|c|c|c|c|c|c|c|}
\hline \multirow[t]{2}{*}{ Type of material } & \multirow[t]{2}{*}{$L(\mathrm{~mm})$} & \multirow[t]{2}{*}{$D(m m)$} & \multirow[t]{2}{*}{$L / D$} & \multicolumn{2}{|c|}{$\rho\left(\mathrm{kg} / \mathrm{m}^{3}\right)$} & \multicolumn{2}{|c|}{$f_{r}\left(\mathrm{~N} / \mathrm{mm}^{2}\right)$} \\
\hline & & & & Ave. & S.D. & Ave. & S. D. \\
\hline \multirow[t]{17}{*}{ L80 } & 500 & 300 & 1.7 & 485 & 1 & 2.11 & 0.16 \\
\hline & & 250 & 2.0 & 481 & 4 & 2.27 & 0.27 \\
\hline & & 200 & 2.5 & 483 & 9 & 2.41 & 0.23 \\
\hline & & 150 & 3.3 & 485 & 6 & 2.15 & 0.20 \\
\hline & & 100 & 5.0 & 488 & 3 & 2.19 & 0.05 \\
\hline & & 80 & 6.3 & 480 & 6 & 2.44 & 0.20 \\
\hline & 200 & 150 & 1.3 & 467 & 7 & 2.45 & 0.10 \\
\hline & & 100 & 2.0 & 465 & 10 & 2.75 & 0.24 \\
\hline & & 80 & 2.5 & 465 & 12 & 2.79 & 0.25 \\
\hline & & 60 & 3.3 & 471 & 11 & 3.39 & 0.34 \\
\hline & & 40 & 5.0 & 468 & 7 & 3.52 & 0.40 \\
\hline & & 20 & 10.0 & 468 & 13 & 4.06 & 0.50 \\
\hline & & 10 & 20.0 & 476 & 16 & 4.79 & 0.35 \\
\hline & 100 & 40 & 2.5 & 494 & 8 & 3.46 & 0.50 \\
\hline & & 30 & 3.3 & 501 & 5 & 3.97 & 0.27 \\
\hline & & 20 & 5.0 & 486 & 11 & 4.07 & 0.53 \\
\hline & & 10 & 10.0 & 496 & 4 & 5.13 & 0.54 \\
\hline \multirow[t]{17}{*}{ L110 } & 500 & 300 & 1.7 & 520 & 7 & 2.49 & 0.49 \\
\hline & & 250 & 2.0 & 517 & 7 & 2.32 & 0.33 \\
\hline & & 200 & 2.5 & 513 & 8 & 2.49 & 0.34 \\
\hline & & 150 & 3.3 & 510 & 2 & 2.60 & 0.21 \\
\hline & & 100 & 5.0 & 503 & 5 & 2.95 & 0.29 \\
\hline & & 80 & 6.3 & 502 & 4 & 3.05 & 0.35 \\
\hline & 200 & 150 & 1.3 & 522 & 6 & 2.61 & 0.28 \\
\hline & & 100 & 2.0 & 523 & 5 & 2.64 & 0.37 \\
\hline & & 80 & 2.5 & 526 & 5 & 3.31 & 0.37 \\
\hline & & 60 & 3.3 & 521 & 8 & 3.22 & 0.51 \\
\hline & & 40 & 5.0 & 529 & 18 & 3.99 & 0.79 \\
\hline & & 20 & 10.0 & 532 & 12 & 4.89 & 0.77 \\
\hline & & 10 & 20.0 & 524 & 15 & 5.54 & 0.52 \\
\hline & 100 & 40 & 2.5 & 513 & 10 & 3.65 & 0.26 \\
\hline & & 30 & 3.3 & 521 & 11 & 3.86 & 0.39 \\
\hline & & 20 & 5.0 & 515 & 14 & 4.51 & 0.34 \\
\hline & & 10 & 10.0 & 522 & 9 & 5.73 & 0.38 \\
\hline
\end{tabular}

The results are presented as the average and standard deviation

$L$ : distance between the fulcrums; $D$ : specimen height; $\rho$ : density; $f_{r}$ : bending strength as determined by Eq. (6); Ave.: average; and S. D.: standard deviation

\section{Comparison of fro with existing data}

\section{on perpendicular-to-the-grain tensile strength}

Figure 17 compares $f_{r \infty}$ and $f_{r}(D=100 \mathrm{~mm})$ obtained in the three-point bending test with existing data on perpendicular-to-the-grain tensile strength. The density of $f_{r \infty}$ is the average value of all the specimens. The existing data are the perpendicular-to-the-grain tensile strengths of softwood species grown in the United States [21] and that of softwood species grown in North Korea [22]. The perpendicular-to-the-grain tensile strengths of the softwood species grown in the United States [21] are the averages of the radial and tangential strengths evaluated according to ASTM D143 [2], and the wood species were bald cypress (Taxodium distichum), cedar (Chamaecyparis thyoides, Calocedrus, Thuja occidentalis, Chamaecyparis lawsoniana, Thuja plicata, and Cupressus nootkatensis), Douglas fir (Pseudotsuga menziesii), fir (Abies balsamea, Abies magnifica, Abies grandis, Abies procera, and Abies concolor), hemlock (Tsuga heterophylla), 

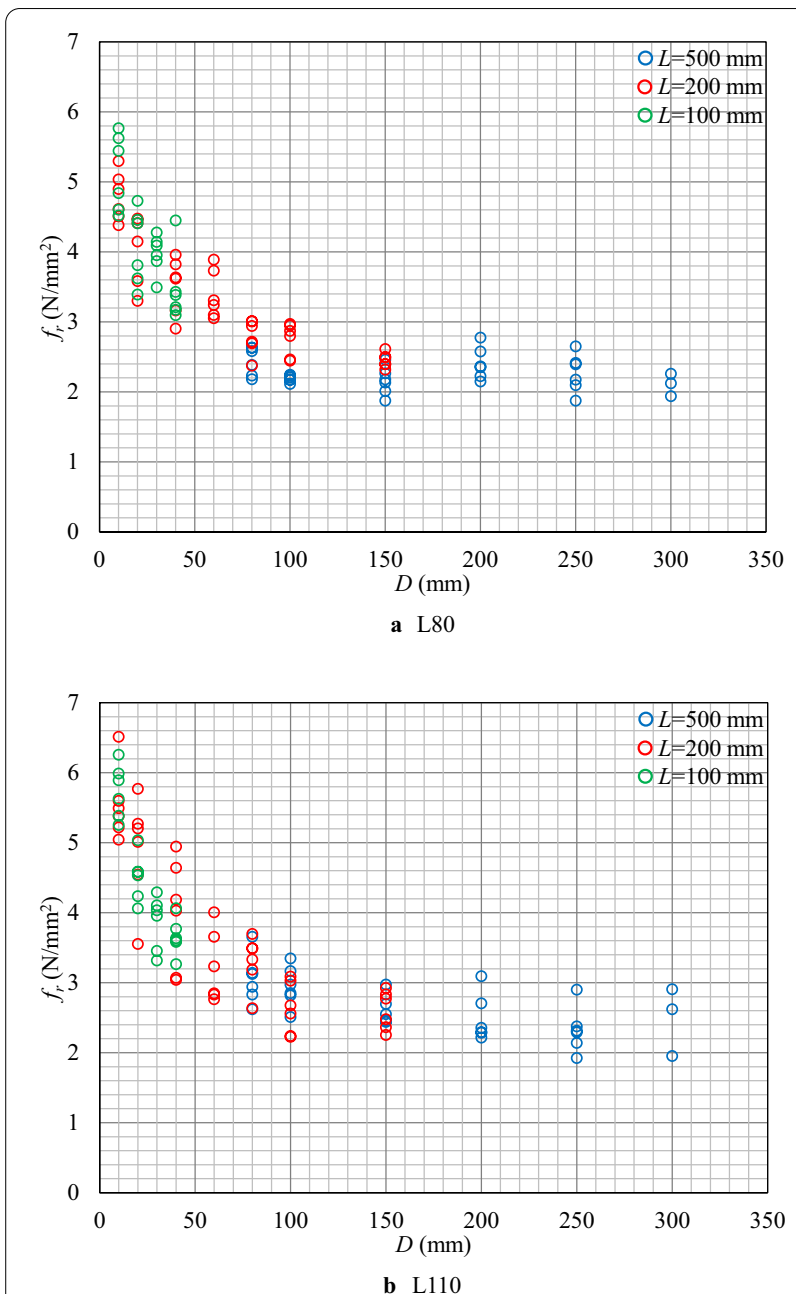

Fig. 9 Relationship between bending strength $f_{r}$ and specimen height $D$ from the three-point bending tests

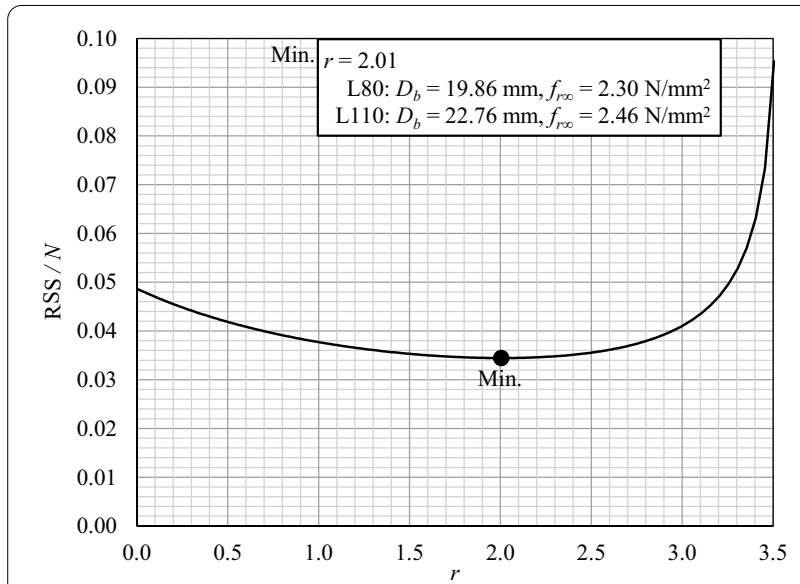

Fig. 10 The residual sum of squares and the optimal values of the parameters for step 1

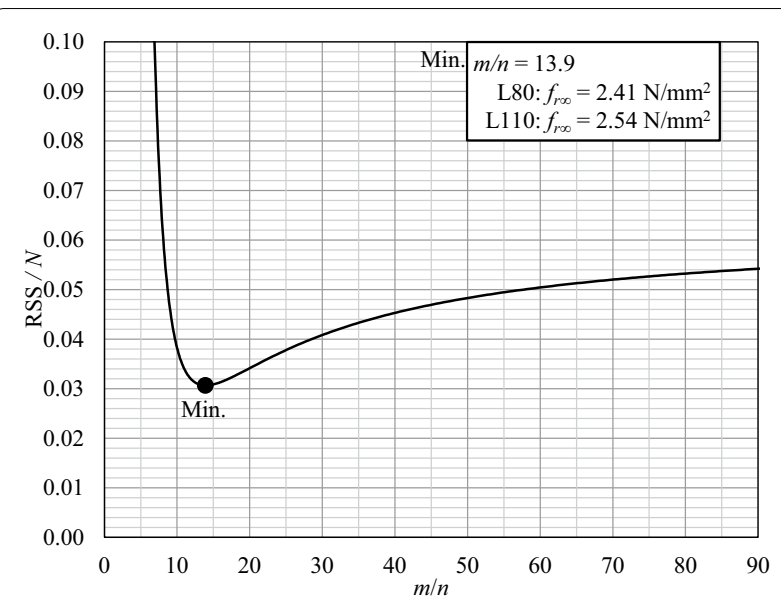

Fig. 11 The residual sum of squares and the optimal values of the parameters for step 2 (first time)

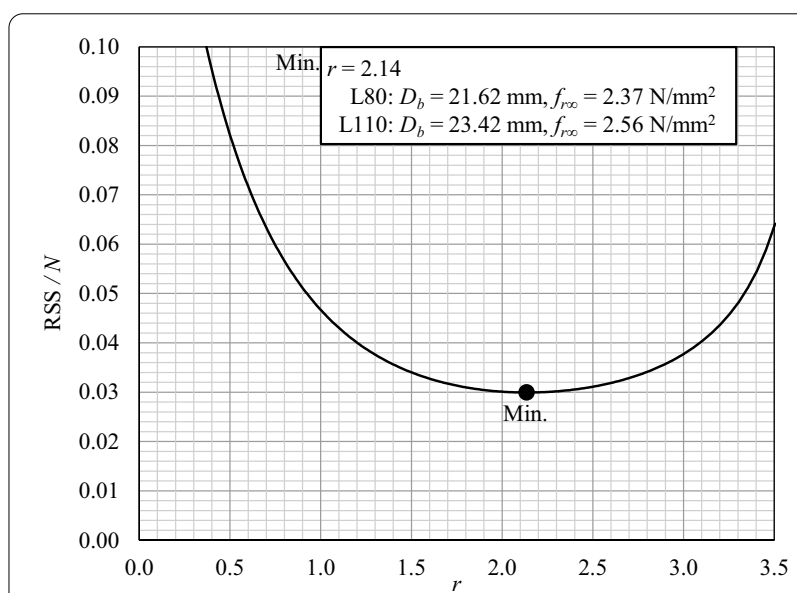

Fig. 12 The residual sum of squares and the optimal values of the parameters for step 3 (first time)

larch (Larix occidentalis), pine (Pinus strobus, Pinus banksiana, Pinus taeda, Pinus contorta, Pinus palustris, Pinus ponderosa, Pinus resinosa, Pinus echinata, Pinus lambertiana, and Pinus virginiana), redwood (Sequoia sempervirens), spruce (Picea engelmannii, Picea rubens, Picea sitchensis, and Picea glauca), and tamarack (Larix laricina). The perpendicular-to-thegrain tensile strengths of the softwood species grown in North Korea [22] can be determined with an equation relating the specific gravity $\gamma$ and tensile strength $f_{t 90}$. This equation was obtained from the relationship between the specific gravity $\gamma$ and tensile strength $f_{t 90}$ of pine (Pinus koraiensis), fir (Abies holophylla), and larch (Larix olgensis) (with moisture contents of 11 to $13 \%$ and a cross-section of $25 \mathrm{~mm} \times 50 \mathrm{~mm}$ ). Although 


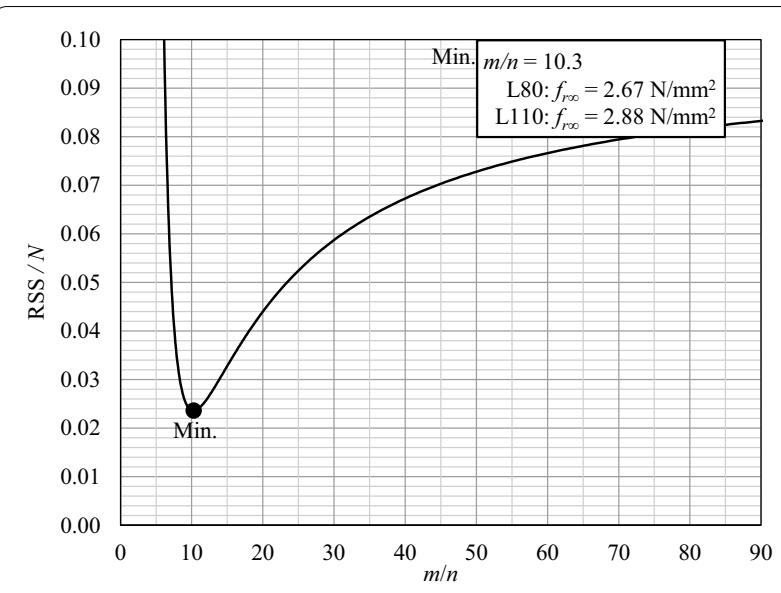

Fig. 13 The residual sum of squares and the optimal values of the parameters for step 2 after convergence

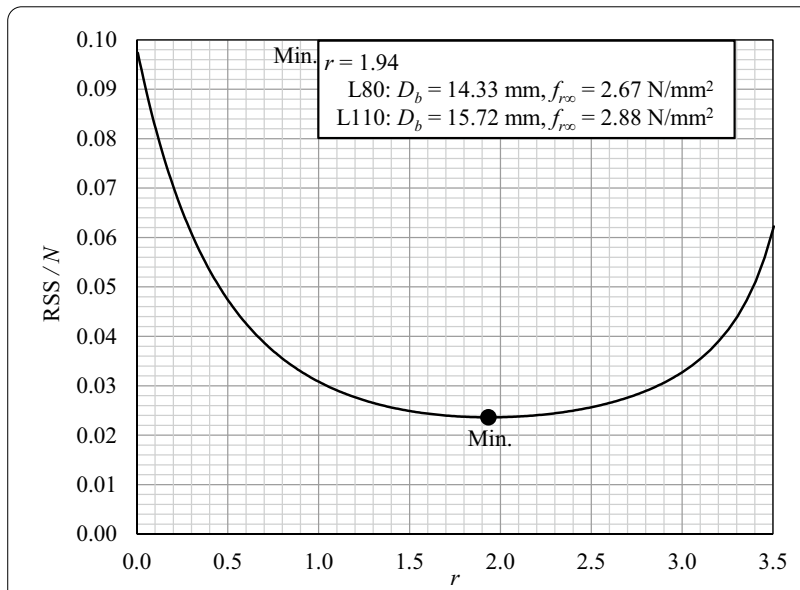

Fig. 14 The residual sum of squares and the optimal values of the parameters for step 3 after convergence

not directly comparable due to differences in testing methods, the existing data and $f_{r \infty}$ were approximately the same.

\section{Conclusion}

In this study, a three-point bending test was conducted on specimens of Scots pine glued laminated timber with different specimen heights to determine the relationship between specimen height and bending strength to failure in tension perpendicular to grain. The experimental results showed that the bending strength decreased as the specimen height increased, but it did not decrease considerably as the specimen height exceeded $100 \mathrm{~mm}$. From the relationship between the bending strength and specimen height, parameters

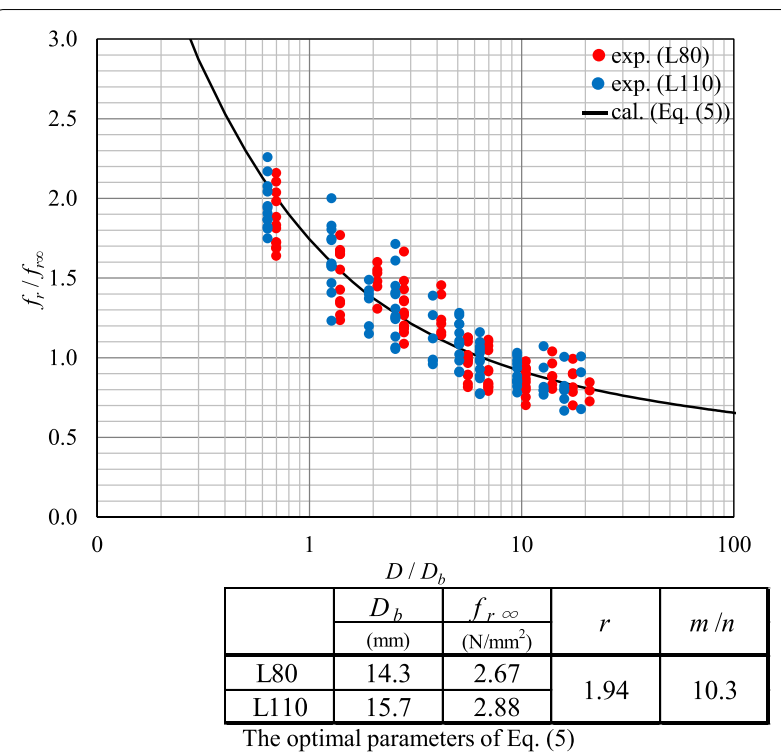

Fig. 15 Relations between $f_{f} / f_{r \infty}$ and $D / D_{b}$ during the three-point bending tests

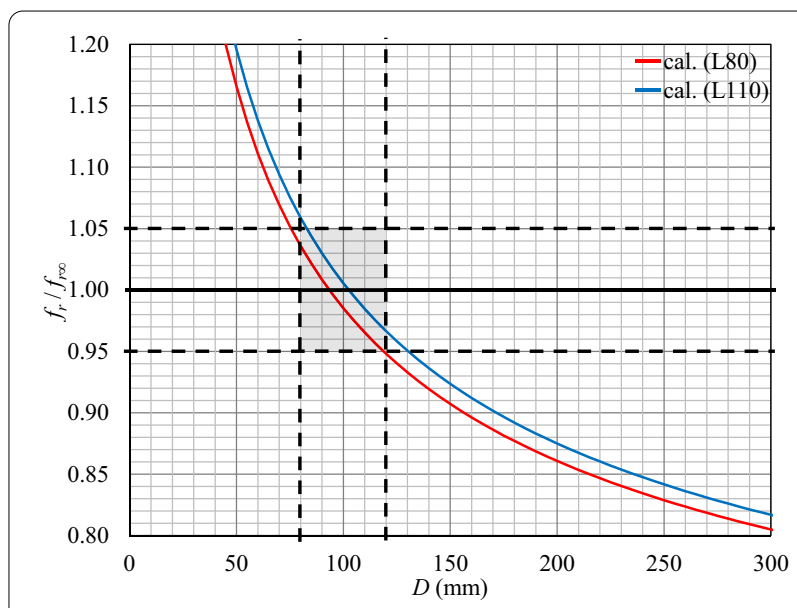

Fig. $16 f_{r} / f_{r \infty}$ of the calculation results in Fig. 15

were then derived that fit Bažant's size-effect law. It was found that for the specimen specifications in this study, the bending strength is equal to the perpendicular-to-the-grain tensile strength at a specimen height of approximately $100 \mathrm{~mm}$. However, it is assumed that the bending strength does not decrease considerably above a certain specimen height, although the specimen height at which the bending strength is approximately equal to the tensile strength perpendicular to the grain, is likely to be different for other species. Thus, it may be possible to establish a bending test method that can measure a slightly conservative perpendicular-to-thegrain tensile strength by investigating specimen heights 


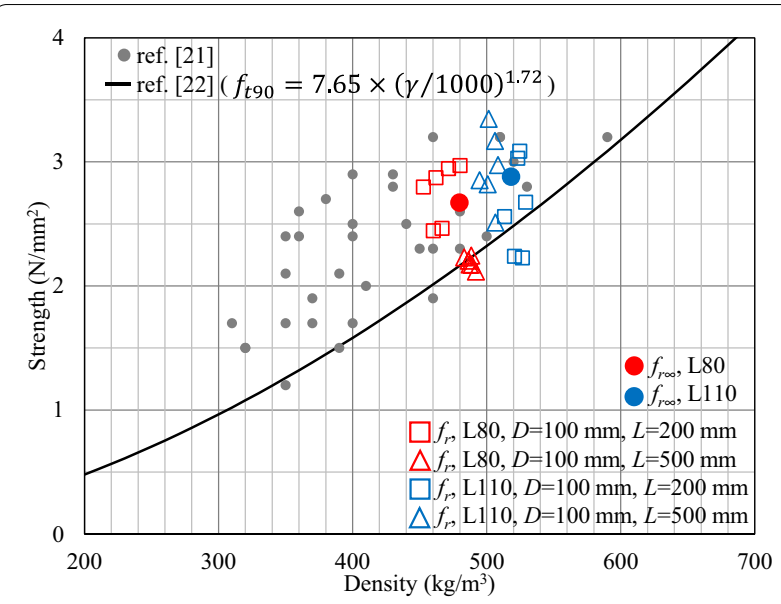

Fig. 17 Existing strength data and experimental values

that do not reduce the bending strength as much in other wood species.

\section{Abbreviations}

L80: L80 grade Scots pine; L110: L110 grade Scots pine; JAS: Japanese Agricultural Standard.

\section{Acknowledgements}

We would like to thank American Journal Experts (https://www.aje.com/) for proofreading this manuscript.

\section{Authors' contributions}

SO planned and implemented the research and wrote the manuscript. All the authors analyzed the results and approved the final manuscript. All authors read and approved the final manuscript.

\section{Funding}

This work was supported by JSPS KAKENHI (Grant numbers 18K13867 and 20K04796).

\section{Availability of data and materials}

All the data generated or analyzed during this study are included in this published article.

\section{Declarations}

\section{Competing interests}

The authors declare that they have no competing interests regarding the publication of this manuscript.

\section{Author details}

1 Graduate School of Human Life Science, Osaka City University, 3-3-138 Sugimoto, Sumiyoshi-ku, Osaka 558-8585, Japan. ${ }^{2}$ National Institute for Land and Infrastructure Management, 1 Tachihara, Tsukuba 305-0802, Japan. ${ }^{3}$ Institute of Wood Technology, Akita Prefectural University, 11-1 Kaieizaka, Noshiro 016-0876, Japan. ${ }^{4}$ Graduate School of Agricultural and Life Sciences, The University of Tokyo, 1-1-1 Yayoi, Bunkyo-ku, Tokyo 113-9657, Japan.

Received: 9 December 2020 Accepted: 12 April 2021 Published online: 20 April 2021

\section{References}

1. JIS Z 2101 (2009) Methods of test for woods. Japanese Standards Association, Osaka (in Japanese)

2. ASTM D143-14 (2014) Standard test methods for small clear specimens of timber. ASTM International, West Conshohocken

3. ISO 13910 (2014) Timber structures — strength graded timber — test methods for structural properties. International Organization for Standardization, Geneva

4. Okusa K (1976) The numerical analysis of the elastic stress on the strengthtest specimens (cleavage, lateral tension, partial lateral compression) of wood. Bull Kagoshima Univ For 4:1-84 (in Japanese)

5. Kuwamura $\mathrm{H}$ (2008) Study on reinforcement of splitting timber by driving wedge test -Study on steel-framed timber structures Part 2-. J Struct Construct Eng Trans AlJ 73(632):1779-1786. https://doi.org/10.3130/aijs.73.1779 (in Japanese)

6. Aicher S, Dill-Langer G, Ranta-Maunus A (1998) Duration of load effect in tension perpendicular to the grain of glulam in different climates. Holz als Roh- und Werkstoff 56:295-305. https://doi.org/10.1007/s001070050323

7. Astrup T, Clorius CO, Damkilde L, Hoffmeyer P (2007) Size effect of glulam beams in tension perpendicular to grain. Wood Sci Technol 41:361-372. https://doi.org/10.1007/s00226-006-0113-6

8. ISO 8375 (2017) Timber structures—glued laminated timber—test methods for determination of physical and mechanical properties. International Organization for Standardization, Geneva

9. Yokobori T (1974) Zairyou Kyoudo Gaku. Iwanami Zensho, Tokyo, pp 209-215 (in Japanese)

10. Hillerborg A, Modéer M, Petersson PE (1976) Analysis of crack formation and crack growth in concrete by means of fracture mechanics and finite elements. Cement Concr Res 6:773-782. https://doi.org/10.1016/00088846(76)90007-7

11. Gustafsson PJ (1985) Fracture mechanics studies of non-yielding materials like concrete: modeling of tensile fracture and applied strength analyses. PhD thesis. Report TVSM-1007, Lund University

12. Boström $L$ (1992) Method for determination of the softening behaviour of wood and the applicability of a nonlinear fracture mechanics model. PhD thesis. Report TVBM-1012, Lund University

13. Bažant ZP (1984) Size effect in blunt fracture: concrete, rock, metal. J Eng Mech 110(4):518-523. https://doi.org/10.1061/(ASCE)0733-9399(1984)110: 4(518)

14. Bažant ZP (1997) Scaling of quasibrittle fracture: asymptotic analysis. Int J Fract 83:19-40. https://doi.org/10.1023/A:1007387823522

15. Bažant ZP (1998) Size effect in tensile and compression fracture of concrete structures: computational modeling and design. In: Mihashi H, Rokugo K (eds) Fracture mechanics of concrete structures (proceedings of the 3rd international conference, FraMCoS-3, Gifu, Japan), Freiburg, Aedificatio Publishers, pp 1905-1922

16. Bažant ZP (1999) Size effect on structural strength: a review. Arch Appl Mech 69:703-725. https://doi.org/10.1007/s004190050252

17. Bažant ZP, Novak D (2000) Energetic-statistical size effect in quasibrittle failure at crack initiation. ACI Mater J 97(3):381-392. https://doi.org/10.14359/ 9879

18. Aicher S (2010) Process zone length and fracture energy of spruce wood in mode-I from size effect. Wood Fiber Sci 42(2):237-247

19. Japanese Agricultural Standard (2007) JAS for Glued laminated timber. Japanese Agricultural Standards Association, Tokyo (in Japanese)

20. Brrett JD (1974) Effect of size on tension perpendicular-to-grain strength of Douglas-fir. Wood Fiber Sci 6(2):126-143

21. Kretschmann DE (2010) Wood handbook, Chapter 5: Mechanical properties of wood. Forest Products Laboratory, Department of Agriculture Forest Service, Madison

22. Kitahara K (1966) Wood physics. Morikitashuppan, Tokyo, p 145 (in Japanese)

\section{Publisher's Note}

Springer Nature remains neutral with regard to jurisdictional claims in published maps and institutional affiliations. 